\title{
Identification of tsunami-induced deposits using numerical modeling and rock magnetism techniques: A study case of the 1755 Lisbon tsunami in Algarve, Portugal
}

\author{
E. Font ${ }^{\mathrm{a}, *}$, C. Nascimento ${ }^{\mathrm{a}}$, R. Omira ${ }^{\mathrm{a}}$, M.A. Baptista ${ }^{\mathrm{a}, \mathrm{b}}$, P.F. Silva ${ }^{\mathrm{a}, \mathrm{b}}$ \\ a IDL-Faculdade de Ciencias da Universidade de Lisboa, Portugal \\ ${ }^{\mathrm{b}}$ ISEL/DEC, Lisboa, Portugal
}

\section{A R T I C L E I N F O}

\section{Article history:}

Received 22 February 2010

Received in revised form 22 June 2010

Accepted 15 August 2010

Edited by: M. Jellinek.

\section{Keywords:}

Tsunami deposit

Beach embayment

Rock magnetism

Numerical modelling

\begin{abstract}
A B S T R A C T
Storm- and tsunami-deposits are generated by similar depositional mechanisms making their discrimination hard to establish using classic sedimentologic methods. Here we propose an original approach to identify tsunami-induced deposits by combining numerical simulation and rock magnetism. To test our method, we investigate the tsunami deposit of the Boca do Rio estuary generated by the 1755 earthquake in Lisbon which is well described in the literature. We first test the 1755 tsunami scenario using a numerical inundation model to provide physical parameters for the tsunami wave. Then we use concentration (MS, SIRM) and grain size ( $\chi_{\text {ARM }}, A R M, B 1 / 2$, ARM/SIRM) sensitive magnetic proxies coupled with SEM microscopy to unravel the magnetic mineralogy of the tsunami-induced deposit and its associated depositional mechanisms. In order to study the connection between the tsunami deposit and the different sedimentologic units present in the estuary, magnetic data were processed by multivariate statistical analyses. Our numerical simulation show a large inundation of the estuary with flow depths varying from 0.5 to $6 \mathrm{~m}$ and run up of $\sim 7 \mathrm{~m}$. Magnetic data show a dominance of paramagnetic minerals (quartz) mixed with lesser amount of ferromagnetic minerals, namely titanomagnetite and titanohematite both of a detrital origin and reworked from the underlying units. Multivariate statistical analyses indicate a better connection between the tsunami-induced deposit and a mixture of Units C and D. All these results point to a scenario where the energy released by the tsunami wave was strong enough to overtop and erode important amount of sand from the littoral dune and mixed it with reworked materials from underlying layers at least $1 \mathrm{~m}$ in depth. The method tested here represents an original and promising tool to identify tsunami-induced deposits in similar embayed beach environments.
\end{abstract}

(c) 2010 Elsevier B.V. All rights reserved.

\section{Introduction}

Tsunamis are unforeseeable phenomena and consequently one of the most devastating natural hazards in terms of human and economical losses. Since the tsunami of Sumatra in 2004 , by far the largest natural catastrophe in human history, the worldwide scientific community has deployed numerous investigations of tsunami deposits to assess tsunami impact. Reconstruction of long-term frequency of paleotsunami is still hard to reach due to the weak conservation of the tsunami deposits in the geological record and to the difficulty in distinguishing them from storm deposits which have similar depositional mechanisms (e.g., Pratt, 2002; Shanmugam, 2006; Tapin, 2007; Dawson and Stewart, 2007; Morton et al.,

\footnotetext{
* Corresponding author at: IDL-Faculdade de Ciencias da Universidade de Lisboa, Edifício C8, $3^{\circ}$ andar, Campo Grande, 1749-016 Lisboa, Portugal. Tel.: +351913782645.

E-mail address: font_eric@hotmail.com (E. Font).
}

2007). Despite their genetic differences, tsunamis and storms both cause brief coastal flooding with high overland flow velocities and strong abrasion and reworking of the nearshore materials. As most nearshore environments are composed by sand, mud and gravel, the distinction between tsunami and storm deposits remains even more difficult.

Here, we test a new method to identify tsunami deposits based upon numerical simulation and rock magnetism techniques coupled with statistical analyses. To test our method we choose the tsunami deposit generated by the 1755 Lisbon earthquake in the Boca do Rio estuary, in Algarve, southern Portugal (Fig. 1), which were dated by thermoluminescence (Dawson et al., 1995; Hindson and Andrade, 1999) and well described in the literature in terms of geomorphologic and sedimentologic features (Hindson et al., 1996; Hindson and Andrade, 1999; Loureiro et al., 2009). The Boca do Rio estuary is a peculiar case of beach embayment where storm waves generally do not overtop the littoral cliff thus providing excellent conditions to preserve the sedimentological record of the 1755 Tsunami. 


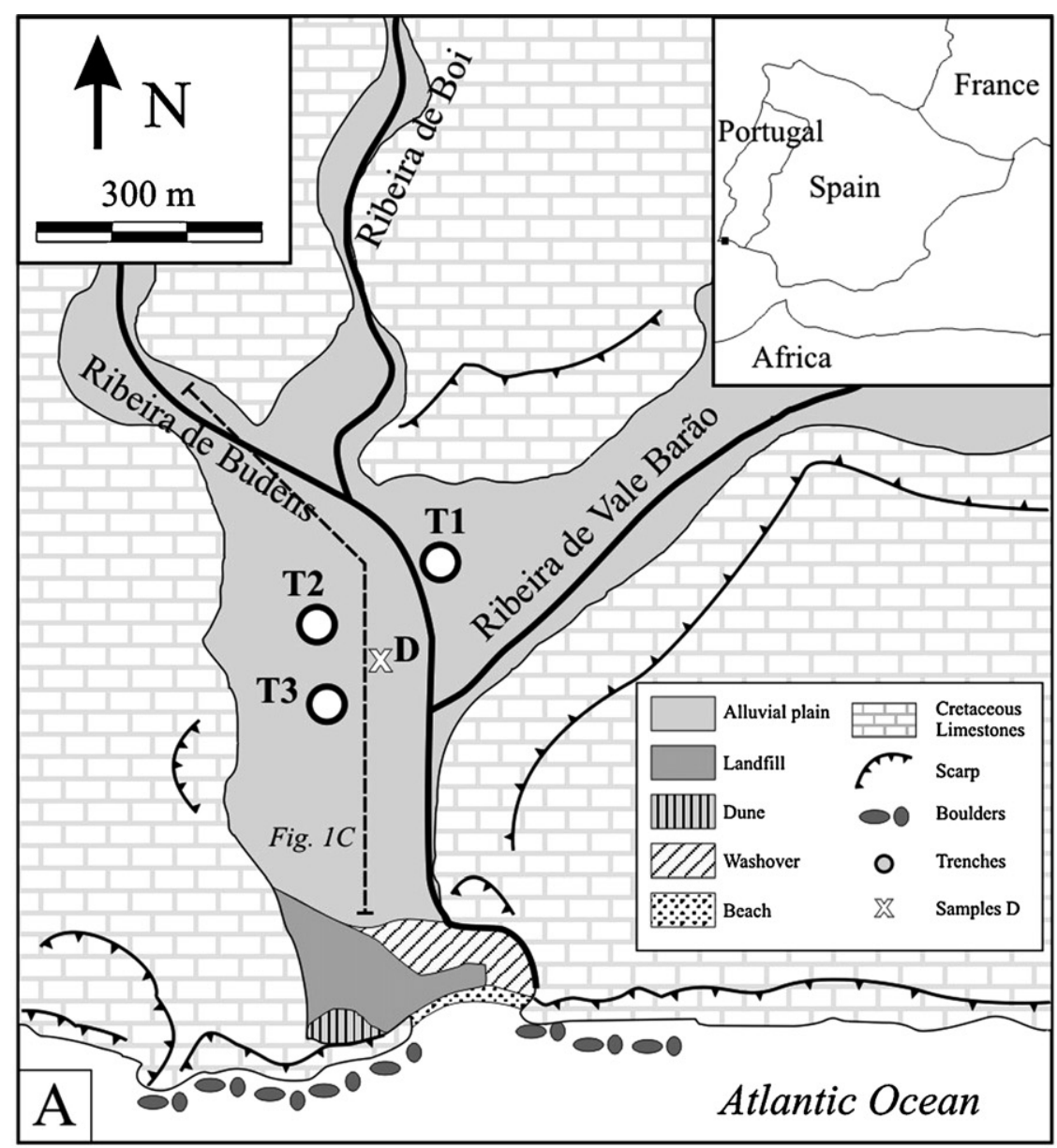

\section{Sedimentological} units

\begin{tabular}{|c|c}
\hline A & Silty clays \\
$(0.8-\mathrm{lm})$ & \\
\cline { 1 - 1 } $\mathrm{B}$ & $\begin{array}{c}\text { Tsunami deposit } \\
\text { sand and gravel }\end{array}$ \\
\hline$(<0.45 \mathrm{~cm})$
\end{tabular}

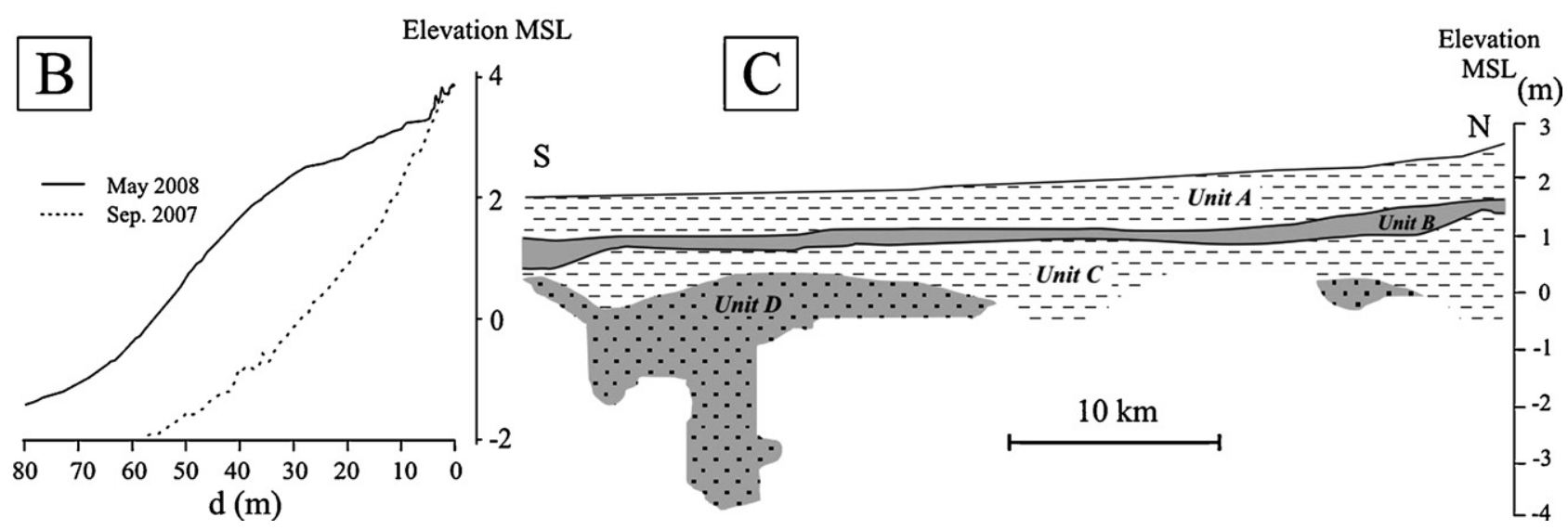

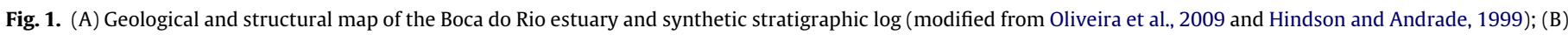

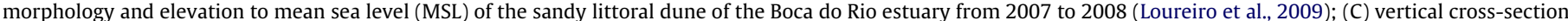
of the Boca do Rio estuary (Hindson and Andrade, 1999; Oliveira et al., 2009).

Recently, Omira et al. (2009a) developed a new numerical inundation model, based on the COMCOT code (Liu and Cho, 1994; Liu et al., 1995, 1998), for the Gulf of Cadiz and the region of Casablanca, Morocco, that could be used to simulated the inundation of the Boca do Rio estuary and to provide physical parameters (i.e. maximum run up, inundation depths and current velocities) for the 1755 tsunami wave. These physical parameters could be further linked to the depositional mechanisms (erosion, transport and deposition) of the tsunami wave by using rock magnetic techniques. Variations of magnetic properties in continuous stratigraphic sections usually reflect changes in the detrital component mineralogy which is largely influenced by cyclic climatic variations (e.g., Ellwood et al., 2007, 2008). In the case of an acyclic event such as bolide impact or even tsunami and storm, which are not controlled by Milankovitch cycles, the brutal change of detrital input into the sedimentary column is easily depicted by an abrupt shift of MS values and thus represents an excellent tracer for our purpose. In counterpart, nature, morphology and distribution of magnetic particles of the tsunami deposit can inform about the origin of the material. Finally, multivariate statistical analyses of magnetic data permit to state the connexion between the tsunami deposit and the underlying layers. Finally, we propose a scenario for the 1755 tsunami deposit that could be used for further investigations of tsunami deposits in embayed beach environments. 


\section{Geological settings and sampling}

Relics of the Tsunami generated by the 1755 Lisbon earthquake, magnitude 8.5-8.75 (e.g., Abe, 1979; Johnston, 1996), were found in the Algarve region, southern Portugal (Hindson and Andrade, 1999), in the estuary of the Boca do Rio (Fig. 1A). The estuary corresponds to a supratidal flood plain separated from the sea by a low shingle and sandy barrier that prevents wave overtopping during storms (Hindson and Andrade, 1999). The lithostratigraphy globally comprises four units namely A, B, C and D (Hindson and Andrade, 1999): Unit A forms the uppermost stratigraphic levels and is composed by reddish silty clay; Unit B corresponds to the Tsunami-induced deposit; Unit C is similar to Unit A in term of sedimentological features but differs in some places where the brown mud grades downwards into a black organic mud with distinct in situ rootlets and plant remains (Fig. $1 \mathrm{~A}$ and C); Unit D corresponds to the base of the sequence and consists of greyish marine sands with shell fragments.

The tsunami deposit (Unit B) is a complex unit that varies laterally in terms of thickness (maximum thickness of $0.45 \mathrm{~m}$ ) and sedimentological features. Hindson and Andrade (1999) identified five sub-units: B1 (fine sand and silt), B2 (sand), B3 (discontinuous lamina of silty clay rich in plant remains), B4 (sand containing shell fragments, gravel and clay balls) and B5 (conglomeratic silty clays with clays balls). The tsunamigenic origin of the Unit B was established through: the thickness $(<0.45 \mathrm{~m})$ of the deposit, the presence of coarse sand and grave, indicating an abrupt break in the low-energy sedimentation of the estuary, the presence of clay balls ripped from the overwash surface of the estuary mud-flats, the presence of different marine species contrasting with the estuarine setting of the depositional environment and the presence of boulders (Hindson and Andrade, 1999). This unit was dated between $1730 \pm 60$ and $1800 \pm 80$ years by thermoluminescence and optically stimulated luminescence and it is coherent with the age of the 1755 Lisbon earthquake (Dawson et al., 1995; Hindson and Andrade, 1999).

In this study a dataset of more than 160 oriented samples ( $2 \mathrm{~cm} \times 2 \mathrm{~cm} \times 2 \mathrm{~cm}$ cubic boxes) was collected from three trenches, namely T1, T2 and T3, in the Boca do Rio estuary (Fig. 1). All trenches include the upper Units A, B (i.e. tsunami deposit) and C; Unit D is represented by two unique samples collected separately using a manual core extractor. Samples were characterized by sedimentological features (C. Andrade, personal communication).

\section{Methodology}

The first step of our approach was to confirm a tsunamigenic origin of the sediment of Unit B and to provide physical parameters (flow depths, inland inundation and run up) for the tsunami wave responsible for its deposition. This objective was done by simulating the tsunami impact at Boca do Rio site using the numerical inundation modelling recently developed by Omira et al. (2009a). These authors proposed five earthquake scenarios based on similar magnitudes $(\sim 8.2)$ but using different fault strikes that affect the tsunami wave directivity. We considered the Marques Pombal scenario which represents the case where energy propagation toward the Algarve region was maximum (Fig. 2A). Tsunami propagation and inundation simulations of the Boca do Rio estuary were done using the COMCOT-Lx code which uses an explicit leap frog finite difference scheme to solve both linear and non-linear shallow water equations on a dynamically coupled system of nested grids (Omira et al., 2009a,b). Three nested grids of different resolutions $(800 \mathrm{~m}, 200 \mathrm{~m}$ and $50 \mathrm{~m}$ ) have been adopted in order to assure a good description of nearshore topographic and bathymetric effects. The digital terrain model (DTM; bathymetry/topography) of Boca do Rio area was generated from a compilation of multisource height/depth data from multibeam surveys, digitalized bathymetric charts and digital cartographic data (Fig. 2B).

It is frequently argued that tsunami waves are much more powerful and abrasive than storm waves (e.g., Morton et al., 2007), having the capacity to erode and rework larger amount of costal materials deep down thus providing some clues to their identification. Once physical parameters of the tsunami wave established, we planned to study the origin of the material constituting the tsunami-induced deposit by using magnetic analyses. If magnetic minerals of the tsunami deposit are "primary", i.e. detrital from terrigenous input, then it could be used to trace the origin of the material constituting the tsunami deposit as well as the transport mechanisms associated to their deposition. Concentration (magnetic susceptibility, IRM), coercivity (B1/2, S-ratio) and grain size $\left(\chi_{\text {ARM }} / \chi\right.$, ARM/SIRM $)$ dependent magnetic proxies were used to characterize the magnetic mineralogy of our samples. Magnetic susceptibility (MS), expressed in $\mathrm{m}^{3} / \mathrm{kg}$, was measured each $15-20 \mathrm{~cm}$ using a KLY-2 kappabridge (Geofizika ent.; sensivity $\left.0.05-200,000 \times 10^{-6} \mathrm{SI}\right)$ and was normalized by the mass of the sample. The $\chi_{\mathrm{ARM}} / \chi$ ratio (dimensionless) was used to investigate relative contributions of superparamagnetic (SP) and single domain (SD) grains to the bulk signal (e.g.; Banerjee et al., 1981; King et al., 1982). ARM/SIRM is also a good indicator of SP particles (Jackson et al., 1993). ARM was induced with an AF field of $100 \mathrm{mT}$ biased with a DC field of $0.05 \mathrm{mT}$ using a LDA-3A demagnetizer coupled with an AMU-1A anhysteretic magnetizer. $\chi_{\text {ARM }}$ was then calculated dividing the values of the induced magnetization $(A / m)$ by the DC field value. Nature and relative amounts of magnetic carriers were checked by Isothermal Remanent Magnetization (IRM) data treated by cumulative-log Gaussian functions (Kruiver et al., 2001). IRM was acquired up to $2.5 \mathrm{~T}$ using an impulse magnetizer IM-10-30 and remanence was subsequently measured with a JR6 magnetometer. IRM data was then processed by the cumulative log Gaussian function (CLG; Robertson and France, 1994) using the software developed by Kruiver et al. (2001). The method permits to characterize magnetic carriers by the SIRM, the $\log B 1 / 2$ (mean coercivity) and the dispersion parameter (DP) and is even reliable for magnetic phases that did not reach the saturation state (Kruiver et al., 2001). To assess the relative contributions of low and high coercive magnetic phases into the sediment, we employed the $S$-ratio (Thompson and Oldfield, 1986). Higher values of the $S$-ratio denote assemblages in which the magnetic properties are dominated by 'soft' (magnetite type) minerals while lower values denote assemblages in which the magnetic properties are more strongly influenced by 'hard' (hematite type) minerals. The $S$-ratio was obtained after applying a DC field of $1 \mathrm{~T}$ (i.e. SIRM) and a subsequent reversed DC field of $0.3 \mathrm{~T}$. S-Ratios was then calculated by the following equation: $S$-ratio $=-I R M-0.3 \mathrm{~T} / \mathrm{SIRM}$. SIRM1T.

Nature, morphology and relative amount of magnetic minerals were determined by Scanning Electron Microscopy (SEM) coupled with Energy Dispersive Spectra (EDS) on carbon-coated rock fragments using a Jeol JSM-6360LV microscope and a Noran Instrument EDS analyzer. To study the contribution of materials that underlay the tsunami deposit, only Units B, C and D were analyzed.

To study the connexion and similarity between the different sedimentological units we applied a multivariate statistical analysis to our magnetic data. The multivariate statistical analysis is a powerful method to identify and correlate specific stratigraphic horizons based on the similarity of their magnetic parameters (Kovach, 1995; Xia et al., 2007). The method is originally dedicated to compare different sections but was applied here to find the connection between the magnetic carriers present in the tsunamiinduced deposit with those of the underlying units. The similarity coefficient (SC) and the Euclidean distance (ED), representing angle and distance between two vectors (two units) in the multidimen- 


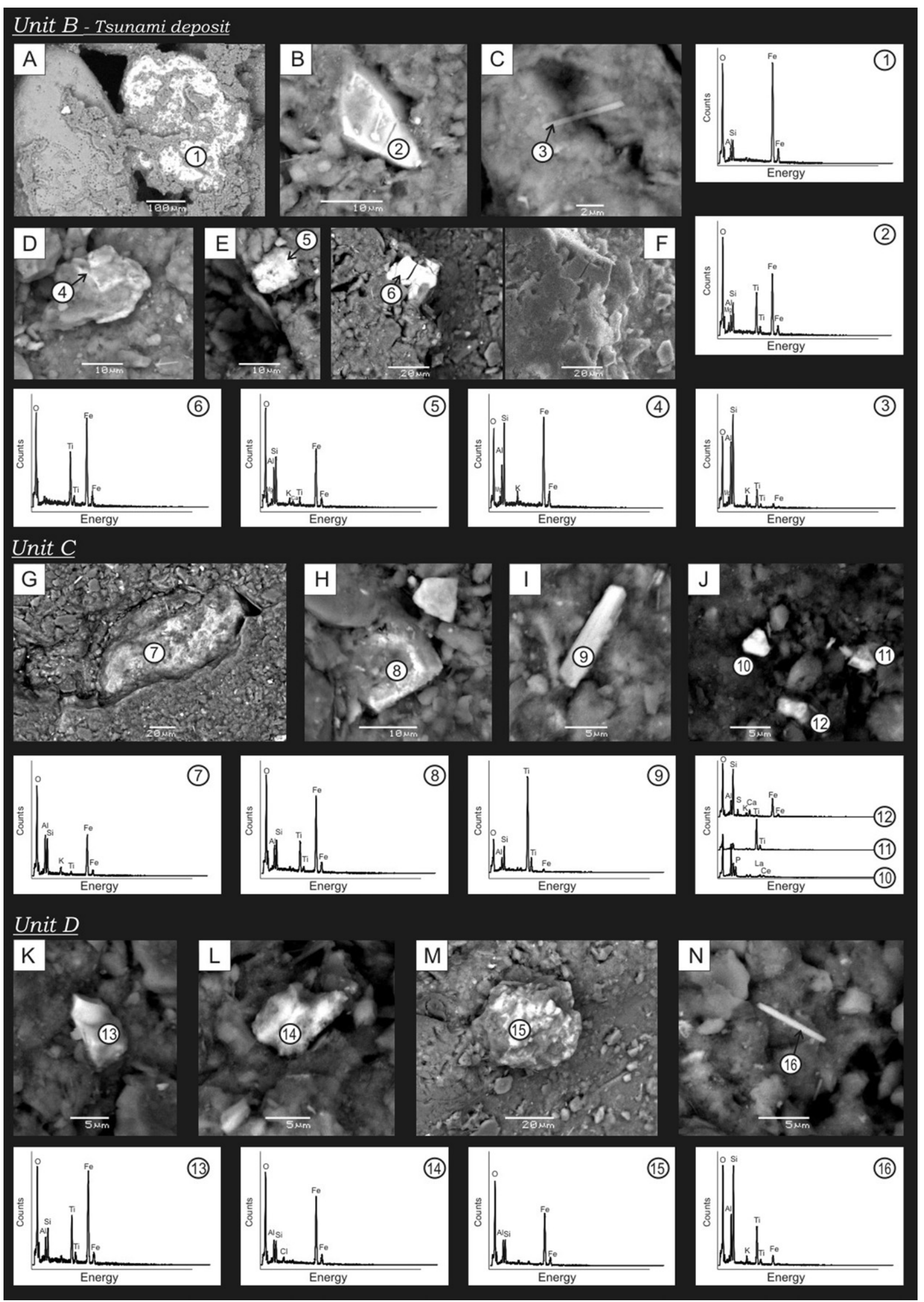

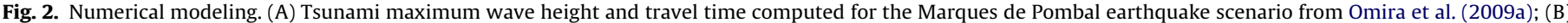
Digital Terrain Model of the Boca do Rio Estuary; (C) inundation map of the Boca do Rio estuary; (D) current velocities in m/s. 
sional space, were calculated by the following equations:

$$
\mathrm{Sc}=\cos \theta_{x y}=\frac{\sum_{k=1}^{n}\left(x_{k} y_{k}\right)}{\sqrt{\sum_{k=1}^{n} x_{k}^{2}} \sqrt{\sum_{k=1}^{n} y_{k}^{2}}}
$$

$\mathrm{ED}(X, Y)=\sqrt{\sum_{i}\left(X_{i}-Y_{i}\right)^{2}}$

where SC is calculated as cosine of the angle between two vectors, $k$ is the magnetic parameter of the two units $x$ and $y$, and $n$ equals 6 in this study. The maximum value of SC is 1 indicating that the two vectors point to the same direction. ED represents the distance between two vectors in a multidimensional space and approximates 0 for identical vector.

\section{Results}

\subsection{Numerical modelling}

To model the propagation and inundation of the Boca do Rio estuary by the tsunami wave generated by the 1755 Lisbon earthquake, we selected the tsunami scenario that proved to be more efficient in radiating energy towards the South Portuguese coast (i.e. the Marques Pombal scenario with $\mathrm{Mw}=8.2$; Miranda et al., 2008; Omira et al., 2009b) (Fig. 2A). Results of our numerical simulation are illustrated in Fig. $2 \mathrm{~B}$ and $\mathrm{C}$ which shows the spatial distribution of the maximum flow depth into the Boca do Rio estuary. It clearly indicates that the tsunami waves overcome the present-day sandy dune of the littoral barrier and inundate the lowland areas of the estuary. The obtained flow depths vary from 0.5 to $6 \mathrm{~m}$ with a maximum inundation distance of approximately $1 \mathrm{~km}$ and a maximum run up of about $7 \mathrm{~m}$. Overland current velocities of the tsunami waves range from 2 to $7 \mathrm{~m} / \mathrm{s}$ and are maximum at the middle part of the estuary (Fig. 2D).

Both velocity and flow depth are the main factors controlling the erosion process due to tsunami impact. Contrary to wind waves that correspond to superficial oscillations, tsunamis involve displacement of the entire water column and consequently have much more capacity to erode when impacting the coast (e.g., Synolakis, 2003). The physical parameters obtained by our simulation are similar to those of the tsunami generated by the 15 November 2006 Kuril earthquake (Mw 8.1-8.4) for which detailed geomorphological costal changes have been described by MacInnes et al. (2009) before and after the event. The authors observed that where areas have relatively low run up $(<8 \mathrm{~m})$ geomorphologic changes are limited to the beach or stream channels whereas in regions where run up are high $(>15 \mathrm{~m})$ the coastline is dramatically altered. In any case, greatest erosion from tsunami occurs closer to the shore (MacInnes et al., 2009 and references therein). By analogy, inundation depths, maximum run up and flow velocities predicted by our numerical simulation are thus compatible with a considerable erosion of the Boca do Rio estuary.

\subsection{Magnetic susceptibility}

MS data for trenches T1, T2 and T3 are shown in Fig. 3. Values of mass specific magnetic susceptibility vary between $4 \times 10^{-8}$ and $3 \times 10^{-6} \mathrm{~m}^{3} / \mathrm{kg}$ and are in the range of typical sedimentary rocks values (e.g., Dearing, 1999; Ellwood et al., 2007). Data show consistent patterns that can be easily correlated within the three profiles. Units $A$ and $C$ present similar MS values while the tsunami deposit (Unit B; $\sim 5 \times 10^{-7} \mathrm{~m}^{3} / \mathrm{kg}$ ) is characterized by an abrupt and negative shift of MS indicative of a very low contribution of ferromagnetic oxides and/or dominance of paramagnetic minerals into the matrix of the sediment (Fig. 3). On the other hand the two samples from the lowermost Unit D show very low MS values, even lower than the tsunami deposit. The relative higher values of MS of both Units $A$ and $C$ in front of Unit D is principally related to facies: Units A-C has a terrigenous affinity, with significant detrital input (i.e. iron oxides), while Unit D has a marine affinity, being composed by sand and shells fragments that are mostly dia- and paramagnetic. In the trench T3 that includes the first $30 \mathrm{~cm}$ below the ground level a positive shift of MS can be identified probably corresponding to an enhancement of magnetic mineral from an additional source.

\section{3. $\chi_{A R M} / \chi$ and $A R M / S I R M$}

$\chi_{\text {ARM }} / \chi$ ratio and ARM data show continuous and smooth variations along the entire stratigraphic sequences except for Unit $B$ and the two samples from Unit D (Fig. 3 ). $\chi_{\text {ARM }} / \chi$ and ARM values are more or less constant between the Units $A$ and $C$ whereas the Unit $B$ is characterized by significant shifts indicative of a relative major contribution of finer particles, probably in the single domain (SD) size. Samples from the Unit D even show higher $\chi_{\text {ARM }} / \chi$ values indicating a strong contribution of fine SD particles. Another minor positive shift of $\chi_{\text {ARM }} / \chi$ values is observed at the top of the Unit A from trenches T1 and T2 and is correlated to T3 by the abrupt change of MS values observed at $0.35 \mathrm{~m}$ below the ground level in the trench $T 3$. In this uppermost interval, $\chi_{\text {ARM }} / \chi$ ratios are globally constant while ARM values increase significantly together with MS values suggesting that it may correspond to a change in magnetic particle content rather than variations of grain size.

Values of ARM/SIRM $>20 \%$ are linked to a very significant contribution of ultrafine particles (SP) to the bulk magnetic properties (Jackson et al., 1993). All samples exhibit values of ARM/SIRM $<5 \%$ indicating that no SP particles are present in the sedimentological unit of the Boca do Rio.

\subsection{CLG analysis of IRM}

Isothermal Remanent Magnetization data were acquired in four samples (1 per unit) and are illustrated in Fig. 4. All samples exhibit similar coercivity spectra (Fig. 4A) suggesting that the nature of the magnetic carriers is mostly the same in all units. A difference among the units is noted in the values of SIRM (IRM at saturation) indicating a significant variation of the concentration of these minerals within the matrix of the sediment (Fig. 4B): Units A and C show similar SIRM values while Unit B, i.e. the tsunami deposit, shows intermediate values between Unit D and Units A-C. The similar values of SIRM in Units $A$ and $C$ is due to the fact that few differences are noted in their sedimentological features, hardly residing in the addition of organic muds and plants remains that are globally diamagnetic. On the other hand, the Unit D is composed by grey marine sand rich in shell fragments, that are mostly dia- to paramagnetic, in an environment influenced by marine settings. Concerning the tsunami deposit, differences in the SIRM values are interpreted to correspond to a mixture of material issued from Units $\mathrm{D}$ and $\mathrm{C}$ corroborating with the presence of mud balls and detrital materials ripped from the underlying formations (Hindson and Andrade, 1999).

Results of the CLG treatment (Kruiver et al., 2001) are shown in Fig. 4C and D and clearly discriminate two magnetic phases that are presents in all units: a low to medium coercive phase probably corresponding to magnetite (or titanomagnetite); and a high coercive phase probably corresponding to hematite (or titanohematite). Because no significant differences are noted in DP and mean coercivity values, it suggests that all sedimentological units were supplied by a unique and common source. 

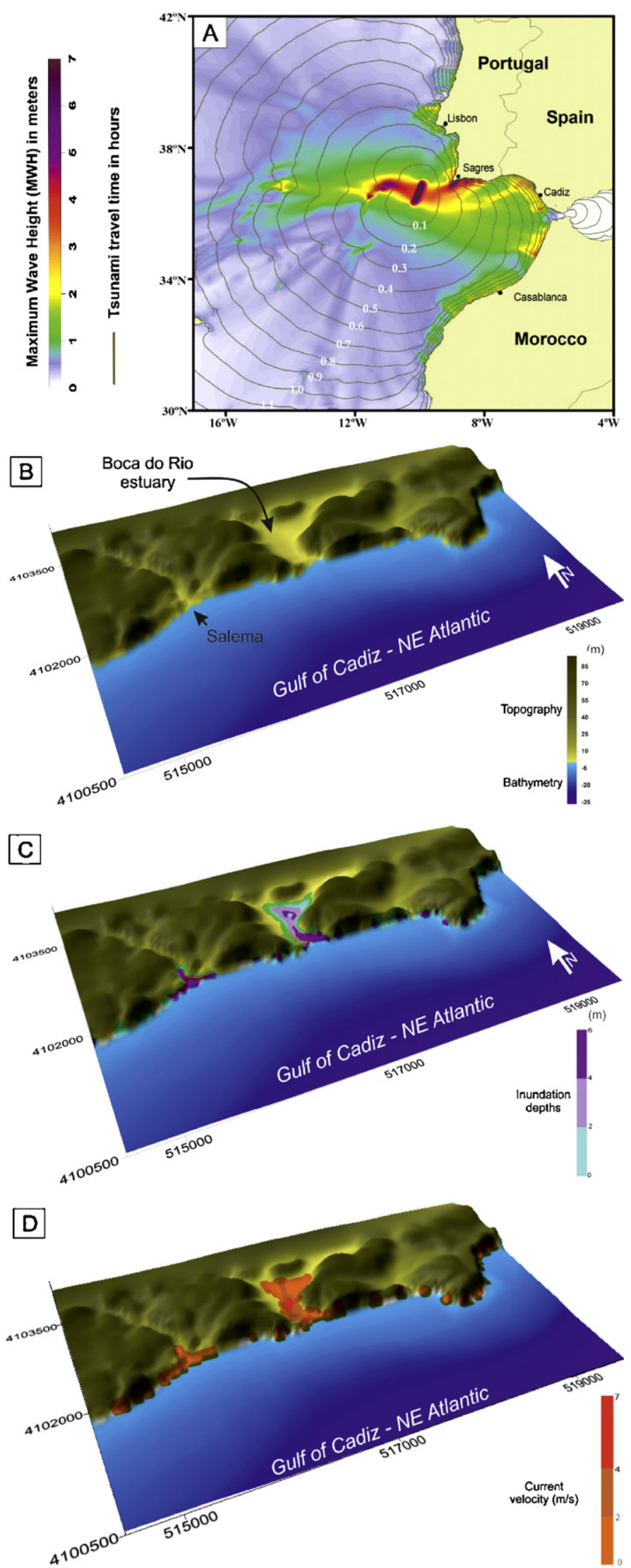

Fig. 3. Isothermal Remanent Magnetization (IRM) curves of samples from Units $A$, $\mathrm{B}, \mathrm{C}$ and $\mathrm{D}$. (A) Induced field (in $\mathrm{mT}$ ) is represented in logarithmic scale; (B) SIRM (in $\mathrm{A} / \mathrm{m}$ ) is represented in logarithmic scale; ( $C$ and $D$ ) results of the CLG treatment using the software developed by Kruiver et al. (2001).

\subsection{S-Ratio}

$S$-Ratios were obtained in 120 samples from the three profiles and are illustrated in Fig. 3. S-Ratio values are $\sim 0.9$ indicating the preponderance of the soft coercive component (magnetite) in front of the higher coercive phase (hematite). In counterpart, variations of the S-ratio could depend on the coercivity characteristics of magnetite/hematite rather than on the relative contribution of highversus low-coercivity phases (Kruiver and Passier, 2001; Liu et al., 2007). In our case, IRM treatment indicates that both low and high coercive phases are represented by relatively homogenous populations of magnetite and hematite as noted by the similarity of $\log$ B1/2 and DP values (Fig. 4). Thus we believe that discrepancy in S-ratio values from the Units A, B, C and D must rather represent differences in contribution of magnetic minerals rather that in coercivity.

In trench T3, a shift in the S-ratio from 0.8 to 0.9 is observed at the top of the sequence, in the first $30 \mathrm{~cm}$ below the ground level. Increase of the $S$-ratio is also correlated to an increase in magnetic susceptibility, ARM and IRM values suggesting an additional contribution of fine magnetic particles from an additional source into the whole magnetic mineralogy. In all trenches, no significant difference of the $S$-ratio is noted between the different units suggesting that the relative contribution of hematite over magnetite is globally the same along the stratigraphic sequence. On the other hand, comparing $S$-ratio with SIRM values indicates that the different units are mostly distinguished by changes in the concentration of the magnetic mineralogy rather than variations in coercivity. Particularly, the tsunami deposit (Unit B) is characterized by very low SIRM values due to a poorly concentrated mixture of magnetite and hematite, in equal proportion than in the other units.

\subsection{SEM observations}

\subsubsection{Unit $B$}

Unit $B$ is characterized by a mixture of large $(>200 \mu \mathrm{m})$ iron oxides (Fig. 5A) and finer ( $5-20 \mu \mathrm{m})$ Ti-rich iron oxides (Fig. 5B, E, and $F)$. A fine-grained population of Ti-rich iron oxides $(<10 \mu \mathrm{m})$ is interpreted to be detrital titanomagnetite as suggested by the presence of relics of exsolution textures (McCabe and Elmore, 1989) (Fig. 5B). A coarser population $(20-40 \mu \mathrm{m}$; Fig. 5F) with semihexagonal structure, eroded borders and significant Ti peaks in EDS spectra probably corresponds to detrital (plate-like) titanohematite (e.g., Kletetschka et al., 2000; Font et al., 2005) as it was depicted by IRM analyses. Highly altered fine $(\sim 10 \mu \mathrm{m})$ iron oxides are also founded coated with clay materials. In addition, needle-like crystals of rutile of $5-10 \mu \mathrm{m}$ in length are found ubiquitously and in high concentration.

\subsubsection{Unit $C$}

Unit $C$ contains abundant Ti-bearing iron oxides homogeneously disseminated into the matrix of the sediment. A population of large and plate-like Ti-poor iron oxides, similar to those observed in Unit $\mathrm{B}$, is represented by crystals of titanohematite (Fig. 5G). Titanomagnetite occurred as euhedral and cube-like crystals embedded in the matrix (Fig. 5H). Needle-like titanium oxides (rutile) are also preponderant and differ from those observed in Unit B by a coarser thickness (Fig. 5I). Very fine-grained iron and titanium oxides $(<5 \mu \mathrm{m})$ are observed occasionally as well as phosphor-rich crystals (Fig. 5J).

\subsubsection{Unit $D$}

Unit $\mathrm{D}$ is composed essentially by a mixture of fine and highly altered Ti-rich and Ti-poor detrital titanomagnetites (Fig. 5K, L, $M)$. Very fine $(<5 \mu \mathrm{m})$ Ti-rich titanomagnetites exhibit surface textures of fractures probably corresponding to a relic of larger original 

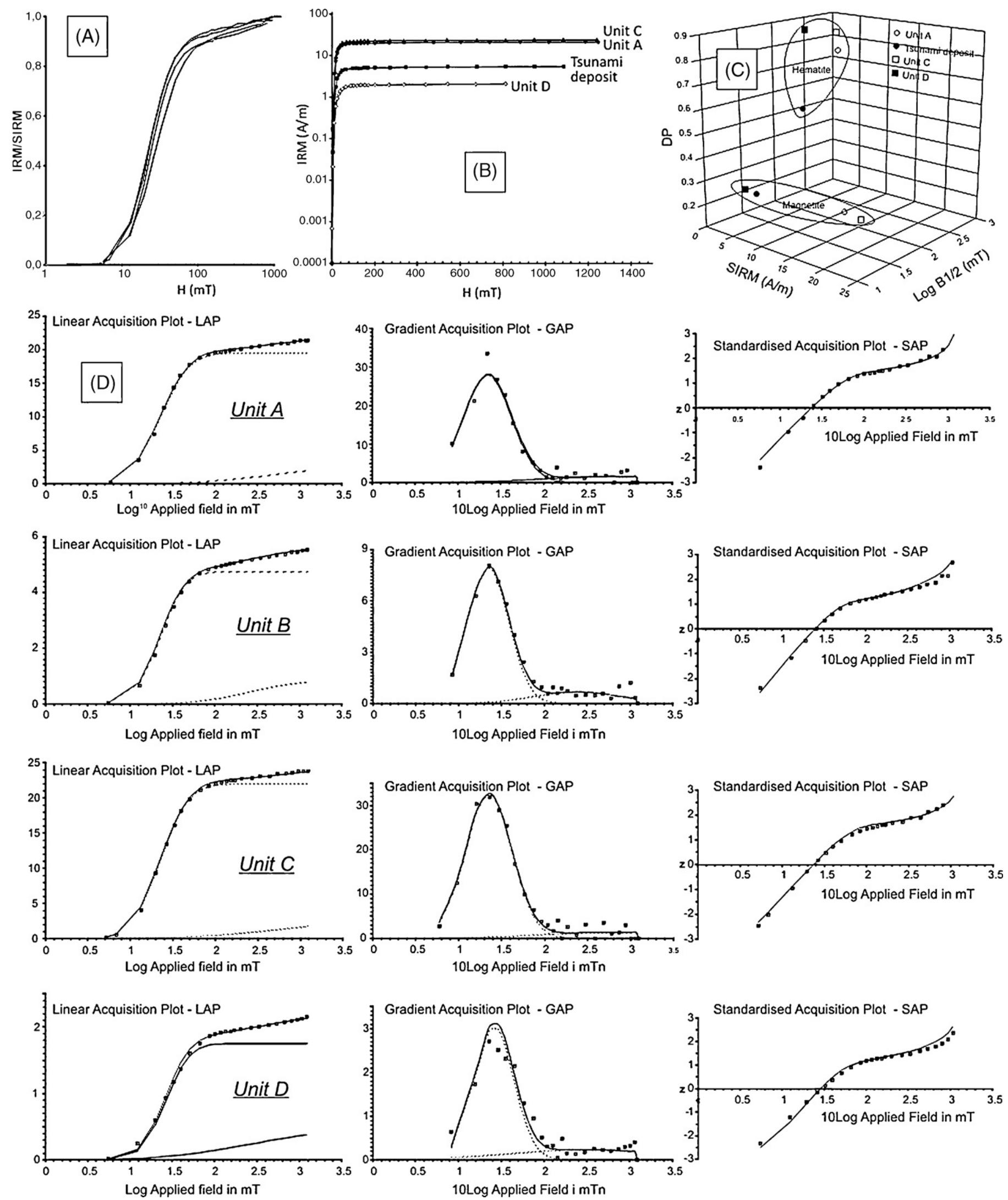

Fig. 4. Scanning electron microscopy (SEM) and energy dispersive spectra (EDS) analyses of samples from Units B, C and D. 
Table 1

Mean values of magnetic parameters for each geological unit and for the three profiles.

\begin{tabular}{|c|c|c|c|c|c|c|}
\hline $\mathrm{T} 1$ & $\operatorname{MS}\left(10^{-5} \mathrm{~m}^{3} / \mathrm{kg}\right)$ & Xarm/X & $\operatorname{ARM}(\mathrm{A} / \mathrm{m})$ & $\operatorname{SIRM}(\mathrm{A} / \mathrm{m})$ & ARM/SIRM & S-Ratio \\
\hline A & 0.201 & 2.84 & 0.287 & 14.77 & 1.99 & 0.93 \\
\hline B & 0.055 & 3.76 & 0.133 & 5.55 & 2.34 & 0.93 \\
\hline C & 0.136 & 3.64 & 0.270 & 10.20 & 2.72 & 0.90 \\
\hline $\mathrm{D}$ & 0.028 & 4.66 & 0.063 & 1.80 & 3.56 & 0.94 \\
\hline$C+D$ & 0.082 & 4.15 & 0.167 & 6.00 & 3.14 & 0.92 \\
\hline \multicolumn{7}{|l|}{$T 2$} \\
\hline A & 0.242 & 2.58 & 0.364 & 21.72 & 1.69 & 0.95 \\
\hline B & 0.065 & 3.14 & 0.100 & 5.35 & 2.04 & 0.91 \\
\hline $\mathrm{C}$ & 0.249 & 2.74 & 0.385 & 18.39 & 2.10 & 0.94 \\
\hline $\mathrm{D}$ & 0.028 & 4.66 & 0.063 & 1.80 & 3.56 & 0.94 \\
\hline$C+D$ & 0.138 & 3.70 & 0.224 & 10.09 & 2.83 & 0.94 \\
\hline \multicolumn{7}{|l|}{ T3 } \\
\hline A & 0.108 & 3.79 & 0.244 & 10.09 & 2.42 & 0.87 \\
\hline $\mathrm{B}$ & 0.044 & 3.35 & 0.093 & 4.80 & 1.87 & 0.92 \\
\hline C & 0.188 & 2.73 & 0.321 & 15.85 & 2.04 & 0.93 \\
\hline $\mathrm{D}$ & 0.028 & 4.66 & 0.063 & 1.80 & 3.56 & 0.94 \\
\hline$C+D$ & 0.108 & 3.70 & 0.192 & 8.82 & 2.80 & 0.94 \\
\hline
\end{tabular}

titanomagnetites (Fig. 5K). On the other hand, Ti-poor titanomagnetites have size varying from 5 to $30 \mu \mathrm{m}$ and have very altered and oxidized states as shown by their botroidal structures (Fig. 5L and $\mathrm{M}$ ).

In all samples, titanomagnetite and titanohematite are ubiquitous and are the principal magnetic carriers of the remanence of the sediments as it was depicted by magnetic analyses. Their distribution within the matrix of the sediment is globally similar between the different units. Presence of titanium, eroded borders of the crystals and the fact that iron oxides occurred well embedded into the matrix point to a primary, i.e. detrital, origin for the magnetic carriers. Some differences into Units B, C and D are found respect to the grain size and morphology of the iron oxides. In Unit D crystals are finer and much more eroded than in Unit $C$ whereas Unit B rather presents a mixture of both populations. These differences could reflect changes in the source, energy of the depositional environment or transport mechanisms.

\subsection{Multivariate statistical analyses}

To compare the tsunami deposits with the other units we calculated first the mean values of the six magnetic parameters in Units A, B, C, and D (Table 1). To avoid any error due to mixture of different materials, layers located at the boundary within two separate units were not included in the mean. In addition, in order to compare the magnetic signature of the tsunami deposits with an eventual mixture of material issued from the abrasion of the underlying units, we have also calculated mean values for Unit $\mathrm{C}+\mathrm{D}$ (Table 1). After applying the multivariate statistical analyses, SC and ED statistic parameters show better similarity between the

Table 2

Multivariate statistical analyses data. SC is the similarity coefficient and ED the Euclidian distance.

\begin{tabular}{llllllr}
\hline Units & T1 & & T2 & & \multicolumn{2}{l}{ T3 } \\
& B & & B & & B & \\
\hline A & SC & 0.90 & SC & 0.89 & SC & 0.97 \\
& ED & 9.27 & ED & 16.38 & ED & 5.34 \\
C & SC & 0.97 & SC & 0.91 & SC & 0.89 \\
& ED & 4.67 & ED & 13.04 & ED & 11.07 \\
D & SC & 0.83 & SC & 0.79 & SC & 0.82 \\
& ED & 4.05 & ED & 4.16 & ED & 3.69 \\
C+D & SC & $\mathbf{1 . 0 0}$ & SC & $\mathbf{0 . 9 8}$ & SC & $\mathbf{0 . 9 8}$ \\
& ED & $\mathbf{0 . 9 9}$ & ED & $\mathbf{4 . 8 4}$ & ED & $\mathbf{4 . 1 4}$ \\
\hline
\end{tabular}

The best correlation is indicated by bold values. tsunami deposits and a mixture of Units C and D (Table 2). This is in agreement with sedimentologic evidences that indicate the presence, into the tsunami deposit, of mud ball materials probably issued from the abrasion of Unit $\mathrm{C}$. These mud balls probably contribute to the whole magnetic signal while the contribution of Unit $\mathrm{D}$ is essentially represented by sand and shell fragments, mostly diamagnetic, and by a relative major contribution of fine-grained magnetic particles.

\section{Interpretation and discussion}

\subsection{A depositional model for the 1755 tsunami deposit of the Boca do Rio estuary}

Our numerical simulation show that 1755 earthquake of Lisbon was strong enough to generated a tsunami wave able to overtop the sandy littoral dune and inundate the estuary $1 \mathrm{~km}$ inland with flow depths of $0.5-6 \mathrm{~m}$. Maximum run up values of $7 \mathrm{~m}$ and current velocities ranging from 2 to $7 \mathrm{~m} / \mathrm{s}$, and by analogy with similar tsunami such as the 15 November 2006 Kuril earthquake (MacInnes et al., 2009), strongly suggest that the 1755 tsunami had strong capacity to erode and affect considerably the morphology of the Boca do Rio estuary.

Magnetic data and results of SEM-EDS analyses of all units are synthesized in Table 3 and, in agreement with our numerical simulation, suggest that the materiel of the tsunami-induced deposit mostly come from the abrasion of the littoral dune and the estuary. We first note that the tsunami deposits of Boca do Rio generated by the 1755 Lisbon tsunami is featured by a characteristic negative MS anomaly indicative of a very low concentration of magnetic particles and/or dominance of paramagnetic minerals (Fig. 3 and Table 3). The paramagnetic dominance is interpreted to be due to the contribution of important amount of sand into the tsunami deposit issued from the abrasion of the sandy littoral dune by the tsunami wave (Fig. 6), as it was shown by mass balance calculation of Oliveira et al. (2009) and our numerical modelling. The presentday dune is about $4 \mathrm{~m}$ above mean sea level with important changes in the geomorphology depending on the season (Fig. 1B; Loureiro et al., 2009). Assuming that a Tsunami-wave similar to the 2004 Sumatra Tsunami could erode more than $4 \mathrm{~m}$ of sands (Paris et al., 2009), Oliveira et al. (2009) consider a dune elevation of 8-12 m and calculate the sand volume retained in the dune and tsunami layer. Their results show that the volume of the pre-existent foredune exceeds by 1.5-3 times the volume of sand deposited in the tsunami layer suggesting that a large fraction of material was exported to the ocean by receding waters. However, the authors indicated slight 

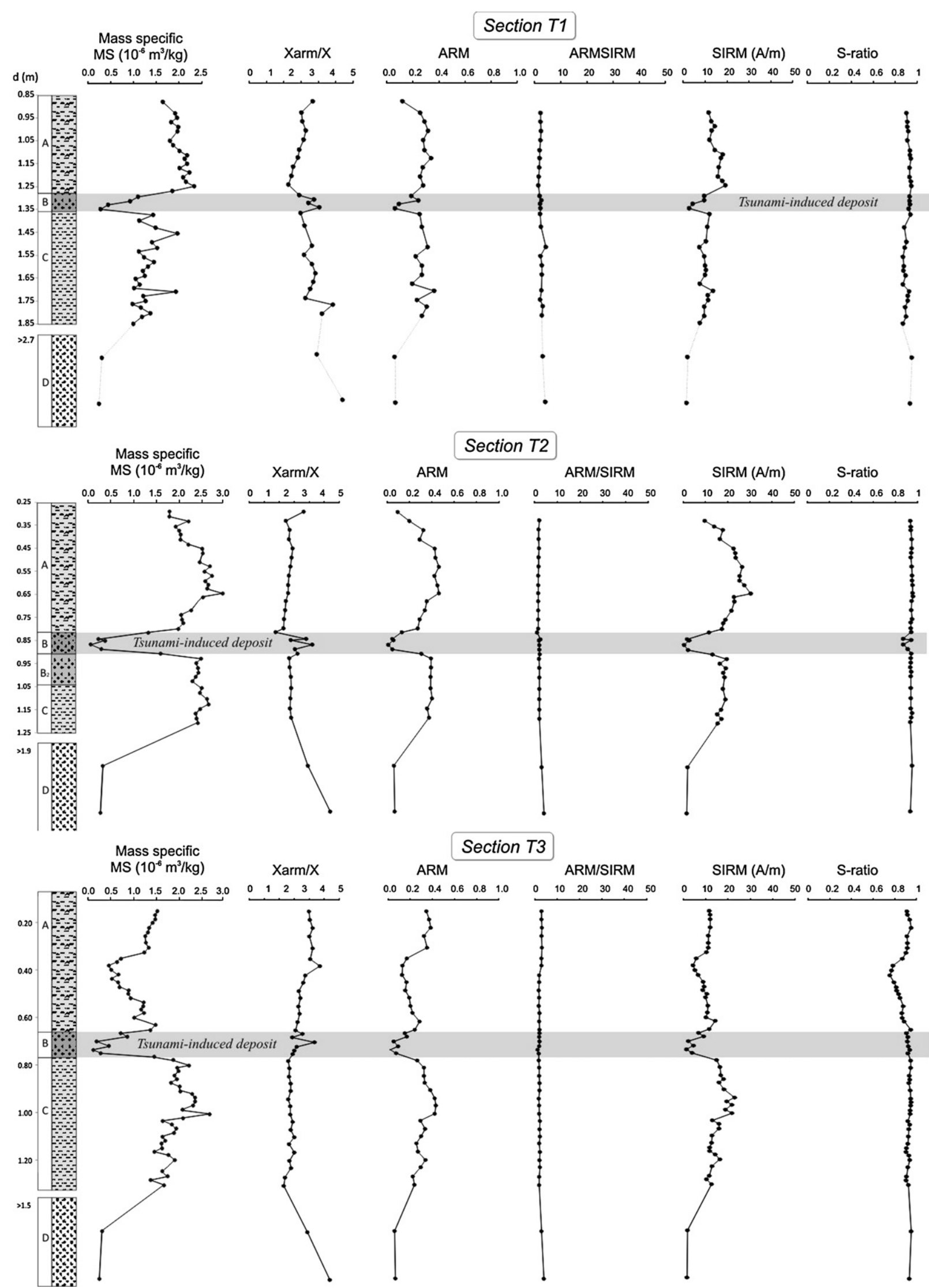

Fig. 5. Magnetic data of trenches $\mathrm{T} 1, \mathrm{~T} 2$ and $\mathrm{T} 3$ from the Boca do Rio estuary. 
Table 3

Summary of magnetic parameters obtained for the three profiles T1, T2 and T3.

\begin{tabular}{|c|c|c|c|c|c|}
\hline & Method & Unit A & Unit B-Tsunami deposit & Unit C & Unit D \\
\hline \multirow[t]{2}{*}{ Magnetic carriers } & \multirow[t]{2}{*}{ IRM/SEM-EDS } & Titanomagnetite & Titanomagnetite & Titanomagnetite & Titanomagnetite \\
\hline & & Titanohematite & Titanohematite & Titanohematite & Titanohematite \\
\hline \multirow[t]{2}{*}{ Proportions } & \multirow[t]{2}{*}{ IRM-CLG/S-ratio } & $\begin{array}{l}\text { Medium coercive } \\
\text { phase: } 87 \%\end{array}$ & Medium coercive phase: $85 \%$ & Medium coercive phase: $90 \%$ & Medium coercive phase: $78 \%$ \\
\hline & & $\begin{array}{l}\text { High coercive } \\
\text { phase: } 13 \%\end{array}$ & High coercive phase: $15 \%$ & High coercive phase: $10 \%$ & High coercive phase: $22 \%$ \\
\hline Grain size & $\mathrm{SEM} / \chi \mathrm{ARM} / \chi$ & - & $>200 \mu \mathrm{m}$ and $5-20 \mu \mathrm{m}$ & $>200 \mu \mathrm{m}$ and $<5 \mu \mathrm{m}$ & $>30 \mu \mathrm{m}$ \\
\hline Morphology & SEM & Eroded & Eroded & Eroded & Eroded \\
\hline Presence of SP minerals & ARM/IRM & No & No & No & No \\
\hline
\end{tabular}

differences in mean grain sizes and sorting of sands contained in the tsunami deposit and suggested that and additional source must have contributed to the supply of the tsunami deposit.

Indeed, magnetic data and SEM observations of our samples suggest that small amount of material issued from the underlying Units $\mathrm{C}$ and $\mathrm{D}$ should have contributed to the formation of the tsunami -induced deposit. Despite of its very low magnetic susceptibility near to the paramagnetic domain, magnetic proxies (SIRM, B1/2, S-ratio) and SEM-EDS analyses indicate that it contains a mixture of ferromagnetic minerals, namely titanomagnetite and titanohematite, with similar morphology and in equal proportions than in Units C and D (Table 3). The average values of MS and SIRM of the tsunami deposit could be interpreted in term of variations in detrital iron oxide contents rather than in changes in coercivity spectra which are mostly similar in all units. SEM obser- vations indicate that both titanomagnetite and titanohematite are of a detrital origin in all units and had suffered significant transport. In addition, ARM and $\chi_{\text {ARM }} / \chi$ data show that the tsunami deposit presents an intermediary grain size distribution between Units C and D (Table 3 and Fig. 3). Results of the multivariate statistical analysis match with the interpretations based on magnetic data indicating a better connection between the tsunami deposit and a mixture of Units $C$ and $D$ (Table 2). All these results points to a scenario where the tsunami wave of the 1755 Lisbon earthquake was strong enough to overtop and erode the sandy littoral dune and reworked magnetic minerals from sedimentological layers situated more than $1 \mathrm{~m}$ below the bottom of the deposit (Fig. 6). This scenario also corroborate the idea that most of the material constituting a tsunami-induced deposit come from the beach and not from offshore as it was already
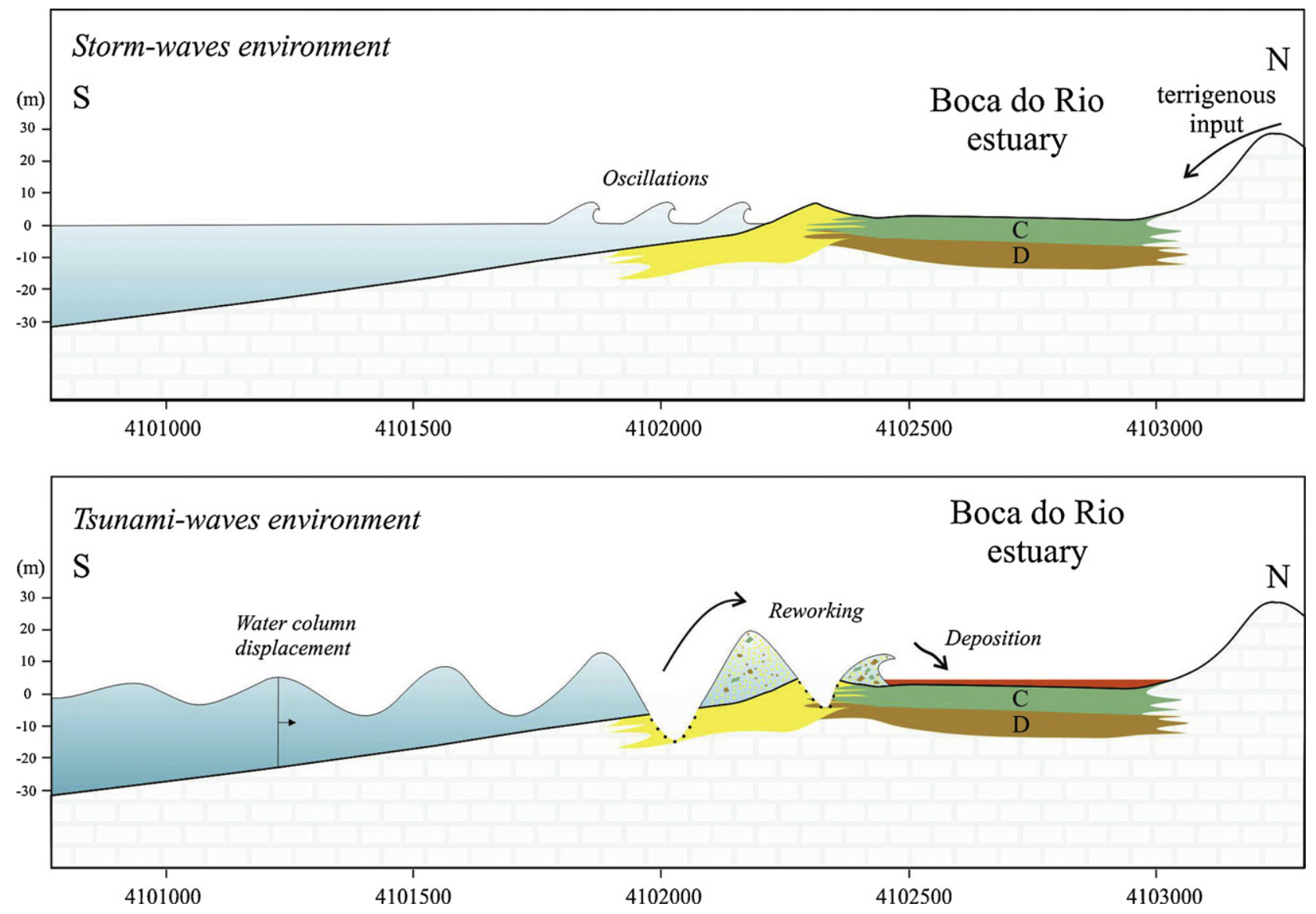

Fig. 6. Synthetic model illustrating the depositional settings of storm- and tsunami-waves in the case of the Boca do Rio estuary. 
stated by recent and paleotsunami field studies and hydro and morpho-dynamic models (e.g., Morton et al., 2007; Young et al., 2010).

\subsection{Reliability of the method}

In the last decades, magnetism has become a useful topic in environmental studies with strong implications in anthropogenic pollution monitoring, climatic variations but also in characterizing depositional mechanisms, mass-transport and time-scale (e.g., Evans and Heller, 2003). However, until now, a magnetic approach to detect tsunami-induced deposits has never been tested in detail. Some recent studies used magnetic susceptibility (MS) on long core sediments to detect anomalous stratigraphic layers with break of sedimentation (Abrantes et al., 2005, 2008; Alt-Epping et al., 2009). This method is based on the fact that cyclic trends in MS datasets in continuous stratigraphic sequences usually result from climatecontrolled fluxes of detrital sediments into the marine environment (Ellwood et al., 2008 and references therein). Long-term variations of MS correspond to orbital changes, i.e. Milankovitch cycles, in the precessional (19-24 kyr), obliquity (41-54 kyr) and eccentricity bands ( $100 \mathrm{kyr})$. This climate cyclicity is often superimposed upon longer-term MS variations resulting from base level changes due to factors such as plate driven processes and eustasy (Ellwood et al., 2008). At a shorter scale, Alt-Epping et al. (2009) studied sediments of the Tagus River in Portugal spending the last 3000 years and show a positive correlation between MS and a reconstructed North Atlantic Oscillations (NAO) index (Cook et al., 2002). Periodic cyclicity of NAO is not well constrained but maximum power spectrum indicate periods ranging from 2 to 70 years (Schlesinger and Ramankutty, 1994; Cook et al., 2002; Massei et al., 2007). In opposite, tsunami-induced deposit are associated to acyclic and catastrophic events that cause a break in the sedimentation regime that can be easily depicted in continuous stratigraphic sections (and with sufficient sedimentation rates) by abrupt negative/positive shifts in MS values. However because these MS anomalies can also be generated by other processes (i.e. storms, hiatus of sedimentation/erosion, anthropogenic contamination, and tectonics), it is not yet sufficient to discriminate without ambiguity a tsunamigenic origin for the corresponding deposit.

Concerning the distinctions between tsunami and storm deposits, they are mostly related to differences in the hydrodynamics and sediment-sorting processes during transport (Morton et al., 2007 and references therein). Tsunami deposition results from high-velocity and long-period waves able to erode sediments from the shoreface and deposit them into the inland. Flows depths of tsunami waves can exceed $10 \mathrm{~m}$ and deposit sediments by decantation during main flooding and after the overland return flow. In opposite, storm waves have weaker flow depths, commonly inferior to $3 \mathrm{~m}$, and depositional mechanisms mostly involve bed load traction with no overland return flow. In the case of the present study, coercivity (log B1/2, S-ratio), concentration (MS, SIRM) and grain size $\left(\chi_{\text {ARM }}, A R M, A R M / S I R M\right)$ dependent magnetic proxies show that most iron oxides of the Unit B deposit come from the reworking of the underlying muddy layers, at least until $1 \mathrm{~m}$ in depth in the lowland part, making the tsunami the most suitable mechanism responsible for such a feature. The method is of a high interest for further investigations of tsunami in beach embayment but still need to be tested in other environments.

\section{Conclusion}

The multidisciplinary approach combining numerical modelling and rock magnetism tested here gives us some insights to identify tsunami-induced deposits and to study the depositional mecha- nisms responsible for their genesis. Our numerical modelling of the Boca do Rio estuary show that the tsunami associated to the 1755 Lisbon earthquake largely overtop the littoral barrier and deposited sediments approximately $1 \mathrm{~km}$ inland with a maximum run up of $7 \mathrm{~m}$, inundation depths of $0.5-6 \mathrm{~m}$ and current velocities of 2-7 m/s. Magnetic data indicate that the tsunami-induced deposit is characterized by a very low magnetic susceptibility linked to important amounts of sand (i.e. paramagnetic) ripped out from the littoral dune and mixed with inland materials reworked by the tsunami wave. Nature, grain size and concentration magnetic proxies indicate that its principal magnetic carriers, namely detrital titanomagnetite and titanohematite, originated from the reworking of the underlying Units $C$ and $D$, situated more than $1 \mathrm{~m}$ in depth. Multivariate statistical analyses match with magnetic data indicating a better connection of the tsunami deposit with a mixture of Units C and D. All these results point to a scenario where the energy released by the tsunami wave was strong enough to outcome and erode important amount of sand from the littoral dune and mixed it with reworked materials from $1 \mathrm{~m}$ in depth. It also confirm previous observations that most of the material constituting a tsunami deposit come from onshore rather than offshore areas. Beyond the results, the method tested here represents an original and promising tool to identify tsunami-induced deposits in similar embayed beach environments.

\section{Acknowledgments}

This work was made in the framework of the research FCT (Fundação para a Ciência e Tecnologia) grants (PTDC/CTEGIX/110205/2009) including the Scientific Initiation Scholarships of Catarina Nascimento and Daniel Almeida (ref. FCUL-CGUL-IDL 01/02). We thank Cesar Andrade for making available samples from the Boca do Rio estuary and for the fruitfull discussions. The authors thank Philippe de Perceval, Thierry Aigouy and Sophie Gouy for their support in SEM analyses and the laboratory of LMTG for making available the equipments. A particular acknowledgment is given to Eduard Petrovsky for scientific support. We greatly thank AnneChristine da Silva for its comments and help in the revision of the manuscript.

\section{References}

Abe, K., 1979. Size of great earthquakes of 1837-1974 inferred from tsunami data. J. Geophys. Res. 84, 1561-1568.

Abrantes, F., Alt-Epping, U., Lebreiro, S., Voelker, A., Schneider, R., 2008. Sedimentological record of tsunamis on shallow-shelf areas: the case of the $1969 \mathrm{AD}$ and 1755 AD tsunamis on the Portuguese Shelf off Lisbon. Mar. Geol. 249 (3-4), 283-293.

Abrantes, F., Lebreiro, S., Rodrigues, T., Gil, I., Bartels-Jónsdóttir, H., Oliveira, P., Kissel C., Grimalt, J.O., 2005. Shallow-marine sediment cores record climate variability and earthquake activity off Lisbon (Portugal) for the last 2000 years. Quaternary Sci. Rev. 24, 2477-2494.

Alt-Epping, U., Stuut, J.W., Hebbeln, D., Schneider, R., 2009. Variations in sediment provenance during the past 3000 years off the Tagus River, Portugal. Mar. Geol. 261, 82-91.

Banerjee, S., King, J., Marvin, J., 1981. A rapid method for magnetic granulometry with application to environmental studies. Geophys. Res. Lett. 8, 333-336.

Cook, E.R., D’Arrigo, R.D., Mann, M.E., 2002. A Well-Verified, Multiproxy Reconstruction of the Winter North Atlantic Oscillation Index since A.D. 1400. J. Clim. 15, $1754-1764$.

Dawson, A.G., Hindson, R., Andrade, C., Freitas, C., Parish, R., Bateman, M., 1995. Tsunami sedimentation associated with the Lisbon earth-quake of 1 November AD 1755: Boca do Rio, Algarve, Portugal. Holocene 5, 209-215.

Dawson, A.G., Stewart, I., 2007. Tsunami deposits in the geological record. Sediment. Geol. 200, 166-183.

Dearing, J., 1999. Environmental Magnetic Susceptibility. Using the Bartington MS2 System, second edition. Chi Publishing, England, p. 54.

Ellwood, B.B., Tomkin, J.H., Febo, L.A., Stuart Jr., 2008. Time series analysis of magnetic susceptibility variations in deep marine sedimentary rocks: a test using the upper Danian-Lower Selandian proposed GSSP, Spain. Palaeogeogr. Palaeoclimatol. Palaeoecol. 261, 270-279.

Ellwood, B.B., Tomkin, Richards, B.C., Benoist, S.L., Lambert, L.L., 2007. MSEC data sets record glacially driven cyclicity: examples from the arrow canyon 
Mississippian-Pennsylvanian GSSP and associated sections. Palaeogeogr. Palaeoclimatol. Palaeoecol. 255, 377-390.

Evans, M.E., Heller, F., 2003. Environmental Magnetism: Principles and Applications of Enviromagnetics. Academic Press (Elsevier), New York, pp. 311.

Font, E., Trindade, R.I.F., Nedelec, A., 2005. Detrital remanence magnetization in hematite-bearing neoproterozoic Puga Cap Dolostone, Amazon Craton: a rock magnetic and SEM study. Geophysical J. Int. 163, 491-500.

Hindson, R.A., Andrade, C., 1999. Sedimentation and hydrodynamic processes associated with the tsunami generated by the 1755 Lisbon earthquake. Quaternary Int. 56, 27-38.

Hindson, R.A., Andrade, C., Dawson, A.G., 1996. Sedimentary processes associated with the tsunami generated by the 1755 Lisbon earthquake on the Algarve coast, Portugal. Phys. Chem. Earth 21, 57-63.

Jackson, M., Rochette, P., Filon, G., Banerjee, S., Marvin, J., 1993. Rock magnetism of remagnetized paleozoic carbonates: low-temperature behavior and susceptibility characteristics. J. Geophys. Res. 98, 6217-6225.

Johnston, A.C., 1996. Seismic Moment assessment of earthquakes in stable continental regions-111. New Madrid 1811-1812, Charleston 1886 and Lisbon 1755. Geophys. J. Int. 126, 314-344.

King, J.W., Banerjee, S.K., Marvin, J., Özdemir, O, 1982. A comparison of different magnetic methods for determining the relative grain size of magnetite in natural materials: some results from lake sediments. Earth Planet. Sci. Lett. 59, 404-419.

Kletetschka, G., Wasilewski, P.J., Taylor, P.T., 2000. Hematite vs. magnetite as the signature for planetary magnetic anomalies? Phys. Earth Planet. Interiors 119, 259-267.

Kovach, W.L, 1995. Multivariate data analysis. In: Maddy, D., Brew, J.S. (Eds.), Statistical Modelling of Quaternary science data. Technical Guide 5. Quaternary Research Association, London, pp. 1-39.

Kruiver, P.P., Passier, H.F., 2001. Coercivity analysis of magnetic phases in sapropel $S 1$ related to variations in redox conditions, including an investigation of the S-ratio. Geophys. Geochem. Geosyst. 2, doi:10.1029/2001GC000181.

Kruiver, P.P., Dekkers, M.J., Heslop, D., 2001. Quantification of magnetic coercivity components by the analysis of acquisition curves of isothermal remanent magnetization. Earth Planet Sci. Lett. 189, 269-276.

Liu, Q., Roberts, A.P., Torrent, J., Horng, C.S., Larrasoaña, J., 2007. What do the HIRM and $S$-ratio really measure in environmental magnetism? G3 8, doi:10.1029/2007GC001717.

Liu, P.L.F., Woo, S.B., Cho, Y.S., 1998. Computer programs for tsunami propagation and inundation. Technical report, Cornell University.

Liu, P.L.F., Cho, Y.S., Briggs, M.J., Synolakis, C.E., Kanoglu, U., 1995. Run-up of solitary waves on a circular island. J. Fluid Mech. 302, 259-285.

Liu, P., Cho, Y.S., 1994. An integral equation model for wave propagation with bottom friction. J. Waterways Port Coastal Ocean Eng. 120, 594-608.

Loureiro, C., Ferreira, O., Cooper, J.A.G., 2009. Contrasting morphologic behaviour at embayed beaches in southern Portugal. J. Coastal Res., SPECIAL ISSUE 56.

MacInnes, B.T., Bourgeois, J., Pinegina, T.K., Kravchunovskaya, E.A., 2009. Tsunami geomorphology: Erosion and deposition from the 15 November 2006 Kuril Island tsunami. Geology 37, 995-998.
Massei, N., Durand, A., Deloffre, J., Dupont, J.P., Valdes, D., Laignel, B., 2007. Contrasting Morphologic Behaviour at Embayed Beaches in Southern Portugal. J. Geophys. Res. 112, doi:10.1029/2005JD007000.

McCabe, C., Elmore, D.R., 1989. The occurrence and origin of late paleozoic remagnetization in the sedimentary rocks of north America. Reviews of Geophysics 27, 471-494.

Miranda, J.M., Baptista, M.A., Terrinha, P., Matias, L., 2008. Tsunamigenic source areas for Portugal mainland, Iberia. Oral Communication, session Tsunami Early Warning Systems and Tsunami Risk Mitigation in the European-Mediterranean Region, 31st General Assembly of the European Seismological Commission, Crete, Greece.

Morton, R.A., Gelfenbaum, G., Jaffe, B.E., 2007. Physical criteria for distinguishing sandy tsunami and storm deposits using modern examples. Sediment. Geol. 200 184-207.

Oliveira, M.A., Andrade, C., Freitas, M.C., Costa, P.J., 2009. Modeling volume transfer between beach-foredune and the backshore by the 1755 Lisbon tsunami at Boca do Rio lowland, Algarve (Portugal). J. Coastal Res., 1547-1551, Special issue, 56.

Omira, R., Baptista, M.A., Miranda, J.M., Toto, E., Catita, C., Catalão, J., 2009a. Tsunam vulnerability assessment of Casablanca-Morocco using numerical modelling and GIS tools. Nat. Haz., doi:10.1007/s11069-009-9454-4.

Omira, R., Baptista, M.A., Matias, L., Miranda, J.M., Catita, C., Carrilho, F., Toto, E. 2009b. Design of a sea-level tsunami detection network for the Gulf of Cadiz. Nat. Haz. Earth System Sci. 9, 1-12.

Paris, R., Wassmer, P., Sartohadi, J., Lavigne, F., Barthomeuf, B., Desgages, E., Grancher, D., Baumert, P., Vautier, F., Brunstein, D., Gomez, C., 2009. Tsunamis as geomorphic crises: lessons from the December 26, 2004 tsunami in Lhok Nga, West Banda Aceh (Sumatra, Indonesia). Geomorphology 104, 59-72.

Pratt, B., 2002. Storms versus tsunamis: dynamic interplay of sedimentary, diagenetic, and tectonic processes in the Cambrian of Montana. Geology 30, 423-426.

Robertson, D.J., France, D.E., 1994. Discrimination of remanence-carrying minerals in mixtures, using isothermal remanent magnetisation acquisition curves. Phys. Earth Planet. Int. 82, 223-234.

Schlesinger, M.E., Ramankutty, N., 1994. An oscillation in the global climate system of period 65-70 years. Nature 367, 723-726.

Shanmugam, G., 2006. The tsunamite problem. J. Sediment. Res. 76, 718-730.

Synolakis, C.E., 2003. Tsunami and Seiche. In: Chen, W.F., Scawthorn, C. (Eds.), Earthquake Engineering Handbook. CRC Press, pp. 9-1-9-90.

Tapin, D.R., 2007. Sedimentary features of tsunami deposits-their origin, recognition and discrimination: an introduction. Sediment. Geol. 200, 151-154.

Thompson, R., Oldfield, F., 1986. Environmental Magnetism. Allen \& Unwin, London.

Xia, D., Chun, X., Bloemendal, J., Chiverrell, R.C., Chen, F., 2007. Use of magnetic signatures to correlate tephra layers in Holocene loessial soil profiles from a small region, SE Iceland. Environ. Geol. 51, 1425-1437.

Young, Y.L., Xiao, H., Maddux, T., 2010. Hydro- and morpho-dynamic modeling of breaking solitary waves over a fine sand beach. Part I. Experimental study. Mar. Geol. 269, 107-118. 